\title{
The Development Stage of Micro Media Apps in China
}

\author{
Tiansheng $\mathrm{Xu}{ }^{1}$, Zhuowen Deng ${ }^{2}$ and Hanglong Song ${ }^{3}$ \\ Capital University of Economics and Business, Information College, China \\ axuts@cueb.edu.cn, b1290905973@qq.com, c1059129753@qq.com
}

Keywords: Micro media; Micro-blog; WeChat; Development trend

\begin{abstract}
Social networking has demonstrated a clear shift towards mobile platforms like smartphone and tablet apps as well as mobile web. Due to the significant development of social networking technology, the number of mobile social media users has been boosted over past 10 years. One of the defining phenomena of the present times reshaping the world as we know it, is the worldwide accessibility to the internet. Micro media comes in many different forms, including WeChat, QQ, business networks, photo-sharing platforms, social gaming, microblogs as well as social networks [1]. In this paper, trend of social networking media in China is discussed.
\end{abstract}

\section{Introduction}

Micro media is a new media type under the new technology support system, which is composed of many independent distributed points. A new form of media, represented by WeChat, micro-blog, is distinguished from the conventional media industries' services. There are a massive number of independent network distributed points [2]. Thus, social media is regarded as a platform for people to share their views, experiences and ideas, including social networking sites, blogs, micro-blog, WeChat, forums and so forth. Besides, social media also can enlighten the users to create new intriguing topics, as people extract and discover what they need on it. Moreover, there are two characteristics that need to be emphasized. One is that it needs a massive number of users; the other is that there must be spontaneous communication. Last but not least, the emergence of social media is dependent on the development of WEB2.0.

\section{Development stage of micro media}

With the continuous promotion of network technology, social networking media makes the information dissemination have the characteristics of mobility, instantaneous and prevalence. The simplification of information content makes its dissemination convenient enough. Thus, micro media provides much more powerful information exchange platform to citizens. Represented by WeChat, microblog, Facebook and twitter, the rise of the various social media platforms worldwide makes information source cover the whole world. Without a doubt, the prospect of the micro media mode in today's market is optimistic. What is more, the rapid development of the micro media changes people's life and work at the same time, it also exerts a subtle influence on people's values, moral values and behavior patterns, as results showed that personality was related to online socializing and information seeking/exchange. In addition, due to the accelerated pace of modern work, the pace of life makes the spread more mobile, trivial, and thus in spare time, concise information content is often more likely to be more people chosen and accepted. Short refining of the dissemination becomes the main target of micro media production, efficient communication channels becomes the main approach of publishing information content for new media.

The usage of micro media at home and abroad. WeChat and Facebook are the most popular domestic and international micro media respectively, both of their proportion of use account for approximately $71 \%$.

China is the world's largest social network market. In China, WeChat has become the most popular micro media application. And a certain client-side had become main trend. WeChat users had 128 friends on average. According to the latest survey of 2016, WeChat average daily login user reached 570 million. 
Table 1 2012-2014 foreign micro media usage

\begin{tabular}{|c|c|c|c|}
\hline & 2012 & 2013 & 2014 \\
\hline Facebook & $67 \%$ & $71 \%$ & $71 \%$ \\
\hline Linkedin & $20 \%$ & $22 \%$ & $28 \%$ \\
\hline Pinterest & $15 \%$ & $21 \%$ & $28 \%$ \\
\hline Instagram & $13 \%$ & $17 \%$ & $26 \%$ \\
\hline Twitter & $16 \%$ & $18 \%$ & $23 \%$ \\
\hline
\end{tabular}

On a worldwide scale, Facebook is the undeniable leader of social networks based on its global reach and active users, with almost 1.6 billion active users around the world as of January 2016. As of the fourth quarter of 2016, Facebook had 1.86 billion monthly active users according to Number of Facebook users worldwide 2008-2016. Active users were those which had logged in to Facebook during the last 30 days.

Penetration and access of Micro media. Regard to Table 2. In the first half of 2014, the most popular instant messengers in China were QQ and WeChat. Both were operated by Chinese internet giant Tencent. Nearly $90 \%$ of users have used instant communication tools. QQ was the most prevalent, the proportion was $77.8 \%$, surpassed any other communication tools. The proportion of WeChat users over the same period made up 65\%. Nevertheless, the coverage rates of Ali Wangwang, YY voice and MoMo were all more than 10\%. From the following data, QQ and WeChat's users access rates were much higher than other social networking tools, as the highest loyalty.

Table 2 Permeability and frequent visit rate in 2014

\begin{tabular}{|c|c|c|}
\hline Application & permeability & Frequency \\
\hline QQ & $77.8 \%$ & $72.5 \%$ \\
\hline WeChat & $65 \%$ & $55.3 \%$ \\
\hline Ali Wangwang & $20.7 \%$ & $9.2 \%$ \\
\hline YY & $14.8 \%$ & $6.9 \%$ \\
\hline Momo & $10.2 \%$ & $4.8 \%$ \\
\hline
\end{tabular}

According to the abroad using frequency analysis, Facebook was the most popular one, the proportion of daily browsing accounted for $70 \%$. What is worth mentioned about is that, in the first quarter of 2015, Facebook monthly active users soared to 15.9 million. Instagram and Twitter daily frequency of use was middle, were occupied by $49 \%$ and $36 \%$. Nevertheless, the ratios of Pinteresty and Linkedin were minimum.

Age distribution of micro media users. According to the survey, teenagers became the main users group, the distribution occupied a proportion of $37.7 \%$. In terms of second largest users group were adults, represented $30.8 \%$, which were followed by middle aged people, took up about $20.7 \%$. Moreover, teenagers had become major users group of Weibo as well, accounted for 53\% of the total number of users. In 2013, after the user growth significantly, adult users accounted for $37 \%$ of the total users. Middle aged and elder user groups accounted for relatively low percentage. Therefore, it was clear that the largest microblog users group were young people.

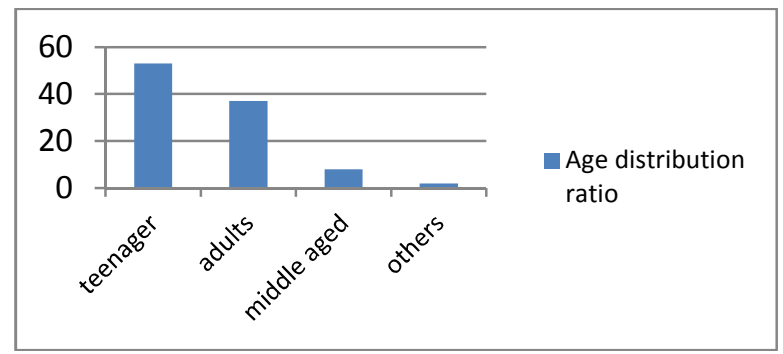

Figure 1 Micro-blog user age distribution in 2013

Apparently, the majority of young people who were under 30 years old took up mostly $27 \%$. Among adolescents, both boys and girls are equally likely to go online, but younger teens. Fully 95\% 
of teens ages 14-17 go online compared with $88 \%$ of teens ages $12-13$. Most of the variance among younger teens is accounted for by 12 years old, of whom $83 \%$ go online compared to $92 \%$ of 13 years old, remain slightly less likely to go online than older teens[3].

Table 3 Facebook user age distribution in 2013

\begin{tabular}{|c|c|}
\hline Age group & Sales volume \\
\hline $18-29$ & $84 \%$ \\
\hline $30-49$ & $79 \%$ \\
\hline $50-64$ & $60 \%$ \\
\hline $65+$ & $45 \%$ \\
\hline
\end{tabular}

By comparing the micro-blog user age distribution with Facebook in 2013, the proportion of elderly users $(65+)$ in foreign countries was much higher than that of the same age groups in China.

Micro media distribution by community type. By comparing the data in 2013 and 2014, only the proportion of the use of the proportion rose in the suburbs, the rest of the region appeared declining trend.

Table 4 Regional distribution of social media at home and abroad

\begin{tabular}{|c|c|}
\hline region & 2013 \\
\hline first-tier & $31.20 \%$ \\
\hline second-tier & $36.60 \%$ \\
\hline
\end{tabular}

Through the analysis of the regional distribution of micro media domestic and abroad, it can be concluded that: the demand of micro media became higher in second tier regions in 2014. And the development inclinations were similar.

Table 5 Facebook use of geographical distribution

\begin{tabular}{|c|c|c|}
\hline region & 2013 & 2014 \\
\hline urban & $75 \%$ & $71 \%$ \\
\hline suburban & $69 \%$ & $72 \%$ \\
\hline village & $71 \%$ & $69 \%$ \\
\hline
\end{tabular}

According to Pew Research Center reports, more than half of rural residents used social media in 2015, those who lived in rural regions were less likely than those in suburban and urban communities to use social media. In $2015,58 \%$ of rural residents, $68 \%$ of suburban residents, and $64 \%$ of urban residents used social media.

The distribution of social media users by education level. Social media users diversified by the level of education, the proportion of users with higher education fell slightly, the proportion of users with primary education increased;

China's Economic Life Survey found that the users range from 26 to 45 years old, who graduated from college or less, tended to spend 2-3 hours a day on their mobile devices. Survey and 360 large data cross-comparison shows that in 2014 the overall Internet users longer than 13 years to extend the 1.36 hours.

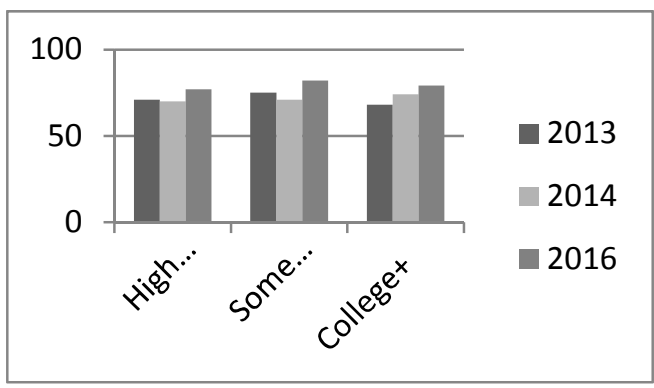

Figure 2 Facebook user education level distribution

This statistic demonstrates the share of internet users in the United States who were using Facebook as of April 2016, sorted by education level. During that period of time, 79 percent of 
internet users who had attained a college degree used the social networking site. Those with at least some college experience have been consistently more likely than those with a high school degree or less to use social media over the past decade. 2013 was the first year that more than half of those with a high school diploma or less used social media [4].

In conclusion, the majority users of social media were undergraduate or higher in China. However, it was opposite in foreign country, especially in the US, the main users were middle classes and the citizens with low education background.

\section{Future Development Analysis}

Nowadays, micro media is crucial to people's live, so that the organizations like government, enterprises, schools, factories are all using micro media platforms which belong to them, It is also demonstrated that the micro media is gradually affecting people's work and behavior. Of course, nothing is more essential than influencing people's behavior, due to that people's behavior indirectly affects people's final decision.

Micro media as a new thing is being accepted by more and more people gradually. Although in the past few years, the public only know its understanding in certain aspects, we need to explore its genuine and potential meanings in future. The next few years, the micro media will improve exponentially in the following points.

(1)Micro media applications will continue to penetrate to the offline entities and facilities. With the rapid development of WeChat, micro shops are also be enhanced, the development of the offline entity will be also growing rapidly.

(2)Micro media applications will pay more attention to improve security, and strive to build a more secure and reliable mobile client-side.

(3)More and more events, such as the micro media reveals that the influence of micro media applications continue to be enhanced, and gradually become a critical force in the guidance of public opinions.

\section{Summary}

To sum up, micro media has four characteristics, such as value added, diversity, communication and selectivity. It also has four functions of reading, writing, managing and spreading. This paper has introduced the development and stage of micro-blog and WeChat in China, including their functions and revolution. It is clear to see that micro media plays a critical role both in our society and business activities in China. Young people who graduate from college are more likely to access micro media than other users group in urban areas.

\section{Acknowledgements}

This paper is supported by Beijing Social Science Fund Project (15ZHB011), National Social Science Fund Project (15AGL001) and Education Improvement Project "research on the influence of intelligent terminal to the learning behavior of college students " of the Capital University of Economics and Business.

\section{References}

[1] https://www.statista.com/topics/1164/social-networks/

[2] Honghong Jiang. From the similarities and differences between WeChat and micro-blog to see the trend of social micro media. News world.

[3] Amanda Lenhart, Kristen Purcell, Aaron Smith, Kathryn Zickuhr Social media and mobile internet use among teens and young adults. February 2010

[4] Andrew Perrin Social Media Usage:2005-2015. October 8, 2015 